\title{
Specific Approach on Dose-Response Curves to Inhaled Carbachol Assessed by the Interruption Technique in Children ${ }^{1}$
}

\author{
CORNELIA WIRZ SOMMER, URS FREY, MARTIN H. SCHÖNLI, AND RICHARD KRAEMER
}

Division of Paediatric Respiratory Medicine, Department of Paediatrics, University of Berne, Berne, Switzerland

\begin{abstract}
To determine significant thresholds obtained by bronchial challenge tests in children for assessment of bronchial reactivity, changes of respiratory resistance $\left(\mathbf{R}_{\text {int }}\right)$ induced by inhaled carbachol were evaluated in 20 asthmatic children $(10$ boys and 10 girls, mean age $9.1 \pm 2.8$ $y$, range 5 to $15 y)$ and 20 healthy control children (10 boys and 10 girls, mean age $12.1 \pm 2.6 \mathrm{y}$, range 8 to $16 \mathrm{y}$ ). Baseline lung function was assessed by whole body plethysmography. The carbachol challenge test was performed by the interruption technique. The objectives were to search for the most predictable provocation dose (PD) according to statistical and practical considerations. The statistical argument is given by the condition that the target $P D$ must definitively be out of the measurement error of baseline values. From the practical point of view, the object is to provoke the subjects the least amount possible. As thresholds of bronchial reactivity, the provocation doses inducing a $50 \%, 65 \%, 75 \%$, or $100 \%$ increase in baseline $R_{\text {int }}\left(P_{50}\right.$, $\mathbf{P D}_{65}, \mathbf{P D}_{75}, \mathbf{P D}_{100}$ ) were computed by a 4th power polynomial function analysis including data points of the entire dose-response curve. In comparison, a new threshold, the "variance based" provocation dose (PD $\left.\mathbf{v b}_{\mathrm{v}}\right)$, was defined as threshold to be definitively above the range of the baseline $R_{\text {int }}$ variation before initiating challenge $\left[P_{v b}>\right.$ mean +2 SD range of $R_{\text {int }}(0)$. Although the $P D_{50}, P_{65}, P_{75}$, and $\mathrm{PD}_{100}$ can be adequately computed by the 4 th power function from the whole dose-response curve, comparison between the different provocation thresholds revealed that $P_{v b}$ gives the best values to differentiate between healthy and asthmatic children $(p<0.002)$. Best cumulative sensitivity and specificity were obtained for $P D_{v b}$ and even at a lower provocation level $(95 \%$ true-negatives at $300 \mu \mathrm{g}$; $95 \%$ true-positives within the range up to $780 \mu \mathrm{g}$ of carbachol), whereas these criteria for $P_{50}$ to $P D_{100}$ are only reached at much higher doses. Therefore, $\mathbf{P D}_{\mathrm{vb}}$ features a mode to determine bronchial reactivity with improved sensitivity and specificity at lowest provocation dose levels. Other advantages are a shorter duration of testing, less occurrence of symptoms and a simpler mathematical approach. (Pediatr Res 34: 478-484, 1993)
\end{abstract}

\section{Abbreviations}

BR, bronchial reactivity

$\mathrm{FEV}_{1}$, forced expiratory volume in $1 \mathrm{~s}$

$\mathrm{MEF}_{50}$, maximal expiratory flow at $50 \%$ of vital capacity

$\mathrm{PD}_{50 / 65 / 75 / 100}$, provocation dose ( $\mu \mathrm{g}$ carbachol) increasing

$R_{\text {int }}$ from baseline $(100 \%)$ to $150,165,175$, or $200 \%$

Received December 5, 1991; accepted April 15, 1993

Correspondence: Prof. R. Kraemer, M.D., Division of Paediatric Respiratory Medicine, Department of Paediatrics, University of Berne, Inselspital, CH-3010 Berne, Switzerland.

'Presented in part at the International Conference of the American Thoracic Society, Miami, FL, May 17-20, 1992.
$\mathrm{PD}_{\mathrm{vb}}$, variance-based provocation dose; threshold significantly above baseline values $\left[R_{\text {int }}(0)\right]$

$\mathbf{R}_{\mathrm{aw}}$, airway resistance, plethysmographically determined

$R_{\text {int }}$, respiratory resistance, measured by the interruption method

$R_{\text {int }}(0)$, baseline respiratory resistance, measured by the interruption method

$s$, sensitivity

$f$, specificity

TGV, thoracic gas volume (end-expiratory resting level, plethysmographically determined)

The procedure of inhalative bronchial challenge tests and its accuracy to assess the degree of BR in a healthy and asthmatic adult population is well standardized and documented (1-6). It has also become a valuable test in children (7-20). Although the bronchoconstrictor responses to physical or natural challenges of exercise, hyperventilation of cold, dry air, and hypo- or hyperosmolar stimuli seem to be more sensitive for asthma but less specific in detecting nonspecific reactivity in nonasthmatic subjects $(21,22)$, the most common way to detect BR in children is the inhalation of an agent such as histamine or acetylcholine derivatives that induce bronchoconstriction. However, despite the usefulness of a pharmacologic test to define the clinical conditions of asthma (6). concluding that a provocation causing a $20 \%$ fall in FEV, supports the clinical diagnosis of asthma currently present in children, some technical conditions should be observed. Forced breathing maneuvers are highly cooperation dependent, which may cause problems in young children. In addition, such test procedures do not allow the reaction of the bronchial system to be followed breath by breath and thus do not fulfill the requirements of safety for routine use in children. Finally, the observation that children have more responsive airways than adults $(10,11)$ has to be taken into account. There exists no satisfying standardization of the most suitable test procedure to ensure safety, to have the least dependency on the child's cooperation, and to offer more convincing data for accurate test $f$ and $s$.

This article reports on a new, safe technique to follow bronchoconstrictor response to carbachol chloride, delivered in standardized quantities, measuring $\mathbf{R}_{\text {int }}$ changes breath by breath. For the analysis of the dose-response curve, different curve-fitting models were used to compute the cumulative doses of carbachol that had been inhaled during subsequent provocation levels in each patient. According to the increase of $R_{\text {int }}(150 \%, 165 \%$, $175 \%$, and $200 \%$ of the baseline value) four response levels $\left(\mathrm{PD}_{50}, \mathrm{PD}_{65}, \mathrm{PD}_{75}\right.$, and $\mathrm{PD}_{100}$ ) were empirically selected and defined. The question was posed whether such a PD in its standard form represents significant provocation thresholds and whether another analytic treatment of the dose-response curve 
would better reflect BR in healthy and asthmatic children, taking into account practicability, safety, and accuracy of the test for the pediatric population.

\section{MATERIALS AND METHODS}

Healthy subjects. Twenty healthy children ( 10 boys and 10 girls, mean age $12.1 \pm 2.6 \mathrm{y}$, range 8 to $16 \mathrm{y}$ ) investigated for other purposes (18) represent the control subjects. Standardized case histories and physical examinations were taken by trained pediatricians and, in case of doubts. histories were verified with the family doctor. The criteria for inclusion into the study were that the child was healthy, especially free from respiratory symptoms, and showed no signs of viral infections or vaccinations during the last $6 \mathrm{wk}$ before the test. Atopic diseases were excluded by determination of normal serum IgE (Pharmacia) and absence of positive radioallergosorbent tests (Phadiatop Kabi Pharmacia. Stockholm. Sweden) for grass pollen, house dust mites, and animals.

Asthmatic children. Twenty asthmatic children with exogenous allergic asthma ( 10 boys and 10 girls, mean age $9.1 \pm 2.8 \mathrm{y}$, range 5 to 15 y) seen at the Paediatric Pulmonary Out-patient Clinic of the University Children's Hospital in Berne, Switzerland, were randomly selected as study patients. In each patient. asthma was diagnosed by a history of recurrent attacks with wheezing, elevated IgE levels (paper radioimmunosorbent test), positive specific IgE (radioallergosorbent) for one or more allergens, and the documentation of airway obstruction $\left(R_{a w}, F E V_{1}\right.$, and $\left.M E F_{50}\right)$, which was reversible with sympathomimetics $(2,4-$ 6 ). At the time of testing, the patients were in a symptom-free interval (no signs of asthma clinically detectable) and the last acute asthma episode was at least $2 \mathrm{wk}$ before the examination. Bronchodilator treatment was withheld $12 \mathrm{~h}$ before, inhalative steroids or disodium cromoglycate $24 \mathrm{~h}$ before the test. None of the patients were on xanthine treatment, systemic steroids, or oral $\beta$-2-agonists.

All parents gave informed consent for the examinations and investigations, and the study was approved by the local ethical committee.

Lung function tests. After the medical interview and a physical examination, pulmonary function tests were performed. The functional abnormalities were evaluated by whole-body plethysmography $(16,23,24)$, using an air conditioned, constant volume, variable pressure whole-body plethysmograph (Jaeger, Würzburg, Germany). TGV at resting level was taken as an estimate of the degree of pulmonary hyperinflation, and $R_{a w}$ as an estimate of the degree of bronchial obstruction. The $R_{a w}$ was determined at half inspiratory flow, the subject rebreathing from a Douglas bag under body temperature pressure saturated conditions. For TGV, static respiratory efforts against the shutter were performed at low frequency and TGV was calculated by the Boyl's law technique. TGV values were corrected for resting expiratory levels of the spirogram. The instrumental dead space of the mouthpiece and the estimated stomach gas volume were subtracted. Based on TGV at end-expiratory resting level, static lung volumes, the total lung capacity, the inspiratory vital capacity, and the residual volume were obtained. $R_{a w}$ was measured during calm breathing (no panting) of air from a Douglas bag. Flow-volume curves gave the $\mathrm{FEV}_{1}$ and the $\mathrm{MEF}_{50}$. Lung function data were expressed as a percentage of predicted values (25).

Bronchial challenge test. Inhalative provocation tests were performed with the Bronchoscreen (Jaeger), a computerized apparatus with a combined nebulizer-shutter head measuring with each breath changes in the $\mathbf{R}_{\text {int }}$. During calm breathing, this technique, originally developed by van Neergaard and Wirz (26) and further improved by Veuilleumier (27) and others (28-31), measures $R_{i n t}$ after interruption of the airflow during $100 \mathrm{~ms}$, from the "opening limb" of the interruption curve (29), during each expiration. $R_{i n t}$ was determined using the formula $R_{i n t}=$ $\left(\mathrm{P}_{\mathrm{alv}} / \mathrm{P}_{\mathrm{ao}}-1\right) \mathrm{R}_{\mathrm{ref}}$, and the pressure in the alveolar compartment $\left(\mathrm{P}_{\mathrm{alv}}\right)$ was obtained indirectly by measuring the mouth pressure after closing the shutter. $P_{a o}$ was the pressure measured during free flow at pressure equilibrium (28). $R_{\text {ref }}$ was a constant known serial resistance. With the subject seated, noseclip in place, the subject breathes air-conditioned ambient air to grow accustomed to the apparatus. Baseline measurements of $R_{\text {int }}(0)$ were performed by inhaling 10 to 20 breaths of physiologic $\mathrm{NaCl}$ solution $(0.9 \%)$ from the built-in dosimeter. Carbachol chloride in saline buffered to $\mathrm{pH} 7.0$ with sodium bicarbonate (Merck Inc., Darmstadt, Germany) was used in a low concentration solution of $1.25 \mathrm{mg} / \mathrm{mL}$ during the first 10 breaths, then in a higher concentration of $2.5 \mathrm{mg} / \mathrm{mL}$ until the end of the test procedure. This protocol was used for safety reasons to immediately detect children reacting to very low doses of carbachol. Generation time for aerosolization was $0.5 \mathrm{~s}$. Multiple nebulizer output measurements revealed a mean output of 44.1 (SD 5.5) $\mathrm{mg}$ of solution per 10 breaths, and 23.1 (SD 1.7) mg per five breaths. Mean values of $R_{i n 1}$ from five breathing cycles were calculated in relation to the cumulative dose at each level of carbachol. Special care was taken to increase the dose gradually, to achieve progressive small changes in $R_{\text {int. }}$. Using this procedure, a doseresponse curve was obtained and the provocation procedure was terminated when an increase of $\mathrm{R}_{\mathrm{int}}(0)$ to $185 \%$ was reached. Thereafter, inhalation was switched to a bronchodilator.

The analytical approach to assess BR in healthy and asthmatic children from the provocation dose-response curves consisted in the computation of the provocation dose at $50 \%, 65 \%, 75 \%$, and $100 \%$ increase of $R_{1 n t}(0)$ ( $P_{50}, P_{65}, P_{75}$, and $\left.P_{1(x)}\right)$.

Fitting model. Starting at $\mathrm{R}_{\mathrm{int}}(0)$, the data were calculated as percent change from the postsaline value of $R_{i n t}$ against the cumulative dose of carbachol (Fig. 1). From previous experiences, the best fit of the dose-response curve was found by a 4th power function using the more general function derived from Charpin's equation (32): $\mathrm{y}=\alpha+\beta \mathrm{x}+\gamma \mathrm{x}^{n}(\alpha, \beta, \gamma>0)$, where the exponent $n$ was assigned values of 2,4, and 6 . In this function, $\alpha$ reflects the constant as intercept. $\beta \mathrm{x}$ the initial linear part. and $\gamma \mathrm{x}^{n}$ the curvilinear part of the dose-response curve. The average coefficient of determination $r^{2}$ for the 4 th power function showed a slightly although insignificantly better fit $(0.85 \pm 0.11) \mathrm{com}$ pared with the 6 th power function $(0.82 \pm 0.21)$. In asthmatic children having high $\mathrm{BR}$, the exponential part of the doseresponse curve must subsequently be weighted in the choice of analytic treatment, whereas in healthy children showing flat. less curvilinear dose-response curves, a more linear fit would be preferable. Using this procedure, the exact interpolation for any measured increase of $R_{\text {int }}$ could be calculated until a dose of 1200 $\mu \mathrm{g}$ of carbachol as the highest dose was administered. According to the increase of $R_{\text {int }}$ to $150,165,175$, and $200 \%$ of $R_{\text {int }}(0)$, the provocation doses $\mathrm{PD}_{50}, \mathrm{PD}_{65}, \mathrm{PD}_{75}$, and $\mathrm{PD}_{100}$ were calculated.

Alternative $P D$ calculation. Having these empirically defined thresholds, not really linked to a biologic phenomenon, and



Fig. 1. Schematic representation of dose-response curves after carbachol challenge in an asthmatic and a healthy child. Dotted areas, range of single values at corresponding level. 
based on the statistical consideration that a bronchial challenge test has be considered positive when $R_{\text {int }}$ significantly increases in relation to $R_{\mathrm{int}}(0)$, the so-called "variance-based" provocation dose $\left(P D_{v b}\right)$ was defined. $P D_{v b}$ represents the threshold where $R_{\text {int }}$ is significantly higher than the individual mean +2 SD of a particular subject at baseline. The validity of these computed provocation thresholds was double-checked by a two-tailed $t$ test looking at the significance of the distribution of $R_{\text {int }}$ measurements on the different provocation levels in relation to the variation of $R_{\text {int }}(0)$ data before the challenge test (Fig. 1). By double-checking the provocation thresholds achieved stepwise using a $t$ test, the changing variance and thus distribution of data points of each provocation level with respect to that at baseline are taken into account.

Statistical methods. Data were analyzed on a Macintosh computer with the statistical package SYSTAT 5.2. Relationships were explored using the $\chi^{2}$ analysis of contingency tables, the Kruskal Wallis test for nonparametric variables, and multiple linear regression analysis. $s$ is defined as the capacity of a test to positively identify those persons with the disease, and $f$ is defined as the capacity of a test to exclude as healthy those subjects who do not have the disease. Therefore, $s$ was calculated as the ratio of the true-positive to the sum of the true-positive plus falsenegatives for the asthmatic population and $f$ as the ratio of the true-negatives and the sum of the true-negatives plus falsepositives in the healthy population.

\section{RESULTS}

Age, sex, and $R_{\text {int }}(0)$ of the 20 healthy and 20 asthmatic children are summarized in Table 1 . Baseline values of lung function measured in the asthmatic children before the challenge tests are given in Table 2 . Both collectives of randomly selected individuals reflect weighed means of corresponding populations. Seven asthmatic children showed lung function within the range of normal, whereas three presented with pulmonary hyperinflation (TGV $>130 \%$ of predicted value), 10 with bronchial obstruction of more central airways $\left(R_{a w}>130 \%\right.$ of predicted value), and nine with obstruction of more peripheral airways $\left(\mathrm{MEF}_{50}<80 \%\right.$ of predicted value), seven of them showing combined functional abnormalities. In addition, the individual values for $\mathrm{PD}_{\mathrm{vb}}$ and $\mathrm{PD}_{50}-\mathrm{PD}_{100}$ are given (Table 1). Whereas for $P_{\mathrm{vb}}$ all doses fell within the range of measured values (to 1200 $\mu \mathrm{g}$ of carbachol) in healthy and asthmatic subjects, an increasing number of subjects (two of 20 to 12 of 20 depending on threshold and/or collective concerned) showed values higher than $1200 \mu \mathrm{g}$ of carbachol and thus would require extrapolation data.

In Figure 2, the five thresholds $\mathrm{PD}_{\mathrm{vb}}, \mathrm{PD}_{50}, \mathrm{PD}_{65}, \mathrm{PD}_{75}$, and $\mathrm{PD}_{100}$ are given. All PD calculated on the basis of the 4th power model showed wide variations, especially in healthy children. Therefore, in comparing data distribution according to Kruskal Wallis, no systematic difference between healthy and asthmatic children could be found. In contrast, PD $_{v b}$, having for both healthy and asthmatic children a much lower mean than PD 50 $(656.8 \pm 292.7 \mu \mathrm{g}$ of carbachol for healthy children; $376.5 \pm$ $265.2 \mu \mathrm{g}$ of carbachol in asthmatics), showed less variation and therefore differentiates significantly between health and disease $(p<0.002)$. Table 3 shows for each of the four computed PD $\left(\mathrm{PD}_{50}, \mathrm{PD}_{65}, \mathrm{PD}_{75}\right.$, and $\mathrm{PD}_{100}$ ) the proportion of threshold values that were higher than the mean $R_{\text {int }}(0)+2 S D$; this was taken as a measure of the accuracy of the PD. Although in asthmatics $100 \%$ accuracy can be achieved for $\mathrm{PD}_{65}, \mathrm{PD}_{75}$, and $\mathrm{PD}_{100}$, in healthy subjects even the $P D_{100}$ reached only $95 \%$ accuracy. By definition, the accuracy of $P D_{\mathrm{vb}}$ is $100 \%$. The discrepancy between both methods is obviously caused by the fact that the method of assessing PD $_{\mathrm{vb}}$ takes full account of the baseline variability. In contrast, the other $\mathrm{PD}\left(\mathrm{PD}_{50}, \mathrm{PD}_{65}, \mathrm{PD}_{75}\right.$, and $\left.P D_{100}\right)$ can give spurious values when variability is proportionally large, an event most likely to occur if $R_{\text {int }}(0)$ is low, or when very hyperreactive subjects (steep exponential dose-response curves) are tested.

In Figure 3, $f$ and $s$ for all five PD are synoptically presented. It can be seen that $f$ and $s$ for $\mathrm{PD}_{\mathrm{vb}}$ both are the most left positioned (lower dose levels). In addition, the $95 \%$ true-negative level for the $f$ of $\mathrm{PD}_{\mathrm{vb}}$ is reached already at $300 \mu \mathrm{g}$ of carbachol and the $95 \%$ true-positive level of $s$ of $\mathrm{PD}_{\mathrm{vb}}$ is up to $780 \mu \mathrm{g}$ of carbachol, whereas these criteria for $\mathrm{PD}_{50}$ to $\mathrm{PD}_{100}$ are at much higher provocation doses. Therefore, $f$ and $s$ for $\mathrm{PD}_{\mathrm{vh}}$ are substantially better than for $\mathrm{PD}_{50}, \mathrm{PD}_{65}, \mathrm{PD}_{75}$, and $\mathrm{PD}_{100}$. One analytic mathematical approach to establish suitability of a test is to depict the crossing point of the declining $f$ curve with the increasing $s$ curve of cumulative percent response (Fig. 3, middle). It can be shown that the crossing point for the $\mathrm{PD}_{\mathrm{vb}}$ is already reached at $480 \mu \mathrm{g}$ of carbachol giving an equalized $f$ and $s$ of $70 \%$. Therefore, $\mathrm{PD}_{\mathrm{vb}}$ features a mode to determine BR with improved $f$ and $s$ at the lowest provocation dose levels.

\section{DISCUSSION}

The objectives of the present study were first to search for a convenient fitting model for dose-response curves of inhalative bronchial challenge tests to obtain accurate provocation thresholds in children. Second, this study intended to identify the best predictable target PD within a lower and upper limit of the dose scale. The former is given by the statistical argument that the target PD must definitively be out of the measurement error of baseline values, and the latter is given by the practical aim to minimize induced airway obstruction. This allows comparison of how well the different provocation thresholds differentiate between health and disease. The question was asked whether an alternative simple calculation of a significant PD would not result in a test procedure that is free from a complex mathematical model, can be applied on-line, and shortens the duration of the test. In this context, the $\mathrm{PD}_{\mathrm{vb}}$ was elaborated. It is defined as the dose corresponding to the first significant increase of flow resistance in relation to the variability of baseline resistance.

It was not the aim of this study to find a mathematical expression that fits all the data points perfectly, or to predict whether the curves are exponential or sigmoid in shape, but to find a mathematical expression that would allow simple computation of different provocation thresholds. Another purpose was to explore differences in constants between normal and asthmatic children; therefore, the mathematical model was chosen for both subject groups. In healthy children, it seems likely that the data points describe a sigmoid function. In asthmatic children, this depends on whether the test procedure was discontinued because of a dramatic exponential increase in airflow resistance. The constants obtained in a previous study $(33,34)$ have not shown any significance in clinical terms, either for $\beta$, indicating the position of the curve, or for $\gamma$ as index of the slope of the dose-response curve.

The validity of our computed curve fits was analyzed by looking at the significance of the distribution of $R_{\text {int }}$ measurements for the different provocation levels in relation to the variation of $R_{\text {int }}(0)$ data before the challenge test. As defined in the present study, $\mathrm{PD}_{\mathrm{vb}}$ is the provocative dose at which respiratory resistance is statistically significantly increased, i.e. outside the range of baseline values (mean $\pm 2 \mathrm{SD}$ ). It is of interest to have the test standardized to achieve a provocation level that is sufficiently high [out of the 2 SD range of variability of $R_{i n t}(O)$ ], but not so high that the patient feels discomfort. Apart from biologic considerations, statistical arguments have an important role to play in establishing a provocation threshold. Especially in children, lung function parameters vary considerably, and with respect to the dose-response curve during bronchial provocation, it must be assumed that variation predominantly in the exponential part of the curve is substantial. By that it can be explained that accuracy, $s$, and $f$ are better for $\mathrm{PD}_{\mathrm{vb}}$. While calculating $\mathrm{PD}_{\mathrm{vb}}$, a direct comparison between the range of individual single 
Table 1. Age and sex distribution, $R_{\text {int }}(0)$, and computed PD obtained in 20 healthy and 20 asthmatic children*

\begin{tabular}{|c|c|c|c|c|c|c|c|c|}
\hline Subject no. & $\begin{array}{l}\text { Age } \\
(\mathrm{y})\end{array}$ & Sex & $\begin{array}{c}\mathbf{R}_{\text {int }}(0) \\
{[\mathrm{kPa} /(\mathrm{L} / \mathrm{s})]}\end{array}$ & $P D_{v b}$ & $\mathrm{PD}_{50}$ & $P D_{65}$ & $\mathrm{PD}_{7 \varsigma}$ & $P D_{1(x)}$ \\
\hline \multicolumn{9}{|l|}{ Healthy children } \\
\hline 1 & 8 & M & 0.54 & 450 & 533 & 564 & 581 & 619 \\
\hline 2 & 8 & M & 0.42 & 1065 & 883 & 996 & 1058 & 1183 \\
\hline 3 & 9 & $F$ & 0.58 & 1060 & 1174 & $>1200$ & $>1200$ & $>1200$ \\
\hline 4 & 9 & $\mathrm{~F}$ & 0.47 & 1200 & $>1200$ & $>1200$ & $>1200$ & $>1200$ \\
\hline 5 & 10 & $\mathbf{M}$ & 0.42 & 430 & 452 & 497 & 523 & 574 \\
\hline 6 & 10 & $M$ & 0.41 & 430 & 617 & 732 & 795 & 924 \\
\hline 7 & 10 & $\mathbf{M}$ & 0.35 & 685 & 618 & 654 & 675 & 720 \\
\hline 8 & 10 & $M$ & 0.39 & 810 & 1019 & 1084 & 1121 & $>1200$ \\
\hline 9 & 12 & $\mathbf{M}$ & 0.32 & 560 & 1000 & 1172 & $>1200$ & $>1200$ \\
\hline 10 & 12 & M & 0.48 & 1060 & 1194 & $>1200$ & $>1200$ & $>1200$ \\
\hline 11 & 13 & $\mathrm{~F}$ & 0.29 & 810 & 631 & 675 & 700 & 754 \\
\hline 12 & 13 & $\mathrm{~F}$ & 0.45 & 430 & 930 & 1047 & 1110 & $>1200$ \\
\hline 13 & 13 & $\mathbf{M}$ & 0.29 & 560 & 1051 & 1190 & $>1200$ & $>1200$ \\
\hline 14 & 14 & $\mathrm{~F}$ & 0.38 & 310 & 456 & 504 & 531 & 585 \\
\hline 15 & 14 & $\mathbf{M}$ & 0.20 & 290 & 493 & 641 & 739 & 986 \\
\hline 16 & 15 & $\mathbf{M}$ & 0.30 & 560 & 513 & 569 & 600 & 664 \\
\hline 17 & 15 & $\mathbf{M}$ & 0.31 & 430 & 960 & $>1200$ & $>1200$ & $>1200$ \\
\hline 18 & 15 & $\mathbf{M}$ & 0.45 & 1065 & $>1200$ & $>1200$ & $>1200$ & $>1200$ \\
\hline 19 & 15 & $\mathrm{~F}$ & 0.23 & 570 & $>1200$ & $>1200$ & $>1200$ & $>1200$ \\
\hline 20 & 16 & $\mathrm{~F}$ & 0.29 & 360 & 673 & 857 & 972 & $>1200$ \\
\hline \multicolumn{9}{|c|}{ Asthmatic children } \\
\hline 1 & 5 & $\mathrm{~F}$ & 0.45 & 320 & 302 & 321 & 332 & 356 \\
\hline 2 & 6 & $\mathrm{~F}$ & 0.45 & 60 & 207 & 270 & 311 & 415 \\
\hline 3 & 6 & $F$ & 0.65 & 310 & 525 & 601 & 642 & 725 \\
\hline 4 & 7 & $\mathrm{~F}$ & 0.45 & 60 & 732 & 951 & 1098 & $>1200$ \\
\hline 5 & 7 & $\mathrm{M}$ & 0.60 & 370 & 1004 & 1112 & 1171 & $>1200$ \\
\hline 6 & 7 & $\mathrm{~F}$ & 0.92 & 60 & 1034 & 1107 & 1149 & $>1200$ \\
\hline 7 & 8 & $\mathrm{~F}$ & 0.62 & 560 & 1036 & 1124 & 1175 & $>1200$ \\
\hline 8 & 8 & $\mathbf{M}$ & 0.54 & 60 & 216 & 281 & 324 & 432 \\
\hline 9 & 8 & $\mathbf{M}$ & 0.75 & 180 & 1051 & 1153 & $>1200$ & $>1200$ \\
\hline 10 & 8 & $F$ & 0.52 & 310 & 1098 & 1173 & $>1200$ & $>1200$ \\
\hline 11 & 9 & $F$ & 0.34 & 560 & 1093 & 1181 & $>1200$ & $>1200$ \\
\hline 12 & 9 & $F$ & 0.50 & 810 & $>1200$ & $>1200$ & $>1200$ & $>1200$ \\
\hline 13 & 9 & $F$ & 0.25 & 310 & $>1200$ & $>1200$ & $>1200$ & $>1200$ \\
\hline 14 & 10 & $\mathbf{M}$ & 0.39 & 240 & 298 & 315 & 326 & 348 \\
\hline 15 & 10 & $\mathbf{M}$ & 0.57 & 790 & 1069 & 1157 & $>1200$ & $>1200$ \\
\hline 16 & 11 & $\mathbf{M}$ & 0.43 & 560 & 1049 & 1124 & 1166 & $>1200$ \\
\hline 17 & 11 & $\mathbf{M}$ & 0.43 & 430 & 560 & 686 & 759 & 908 \\
\hline 18 & 14 & $\mathbf{M}$ & 0.34 & 310 & 273 & 314 & 337 & 382 \\
\hline 19 & 14 & $\mathbf{M}$ & 0.49 & 240 & 277 & 318 & 341 & 386 \\
\hline 20 & 15 & $\mathrm{M}$ & 0.46 & 990 & 1037 & 1132 & 1167 & $>1200$ \\
\hline
\end{tabular}

* PD expressed in $\mu \mathrm{g}$ of carbachol. PD $>1200$ means data points were outside the range of measured $\mathrm{R}_{\mathrm{int}}$.

measurements on each consecutive dose level with the range of initially measured baseline values is computed by $t$ test statistics. This approach is independent from any assumptions about the underlying shape of the dose-response curve and therefore generally applicable. By taking $\mathrm{PD}_{\mathrm{vb}}$ as target $\mathrm{PD}$, better $s$ and $f$ are achieved, even at lower dose of the challenging agent. Another desirable feature of any analytical procedure is that it helps limit the test time to a minimum while producing accurate results. We would speculate that, based on the data obtained by the new calculation of $P D_{\mathrm{vb}}$, discrimination between healthy and asthmatic children could be improved.

Limits of methods. The interruption technique to measure $\mathrm{R}_{\mathrm{int}}$ as an estimate of respiratory resistance has not been widely used, partly because the equipment is expensive and partly because of theoretical reservations regarding the validity of the method. Recent theoretical analyses by Bates et al. $(35,36)$ suggest that the method is essentially valid, although upper airway compliance may cause $R_{i n t}$ to underestimate the true value of $R_{a w}$. Upper airway compliance can be minimized by supporting the cheeks and pharynx. Experimental work in dogs by Bates $e t$ al. (37) shows that in open-chested dogs $R_{\text {int }}$ closely approximates $\mathbf{R}_{\mathrm{aw}}$ even in the presence of parallel heterogeneity. In closed- chested dogs, $R_{\text {int }}$ is strongly correlated with airway resistance even in the presence of bronchoconstriction but includes a contribution from the chest wall and therefore tends to exceed $R_{a w}(38,39)$. More recently, close correlation was found comparing $R_{i n t}$ and $R_{a w}$ in 43 adult patients (40). Changes in $R_{i n t}$ after use of a bronchodilator were similar to those in $R_{a w}$, and the comparison of the average percentage change was within $2 \%$. Acceptability was also checked in 103 -y-old asthmatics showing an increase of $R_{\text {int }}$ after methacholine and a decrease after salbutamol (39). In view of this recent theoretical and practical work and the advantages of the method, this technique provides an instantaneous, breath by breath measurement of respiratory resistance that can be successfully used in a pediatric population.

The form of the algorithm used to extrapolate mouth pressure to obtain $\mathbf{R}_{\text {int }}$ requires further evaluation. Bates et al. have suggested a more sophisticated exponential procedure (36). In cases where pulmonary hyperinflation is present and thus the site of resistance lies upstream (on the alveolar side) of a compliant compartment, true airway resistance is underestimated (31). Therefore, we already proposed to apply an entire resistance-capacitance-inertance model to obtain a more reliable estimation of $R_{\text {int }}(31)$. 
Table 2. Lung function data of 20 asthmatic children, measured before carbachol challenge test*

\begin{tabular}{crrrrrr}
\hline Subject & TLC & TGV & RV & R $_{\text {aw }}$ & FEV & MEF $_{\text {s0 }}$ \\
\hline 1 & 103 & 106 & 129 & 62 & 74 & 64 \\
2 & 101 & 106 & 70 & 118 & 91 & 64 \\
3 & 97 & 90 & 100 & 184 & 85 & 67 \\
4 & 92 & 144 & 78 & 64 & 122 & 116 \\
5 & 113 & 109 & 145 & 135 & 104 & 106 \\
6 & 80 & 85 & 94 & 149 & 75 & 75 \\
7 & 101 & 77 & 56 & 122 & 91 & 132 \\
8 & 102 & 85 & 57 & 103 & 98 & 83 \\
9 & 118 & 131 & 137 & 150 & 84 & 70 \\
10 & 89 & 98 & 122 & 142 & 78 & 71 \\
11 & 103 & 74 & 87 & 125 & 114 & 98 \\
12 & 87 & 91 & 61 & 112 & 107 & 106 \\
13 & 88 & 74 & 75 & 67 & 93 & 113 \\
14 & 124 & 137 & 148 & 141 & 89 & 72 \\
15 & 92 & 100 & 102 & 133 & 80 & 100 \\
16 & 88 & 81 & 68 & 171 & 90 & 73 \\
17 & 87 & 80 & 103 & 107 & 93 & 106 \\
18 & 94 & 125 & 73 & 128 & 92 & 85 \\
19 & 82 & 83 & 97 & 172 & 79 & 77 \\
20 & 95 & 81 & 88 & 148 & 100 & 110 \\
\hline
\end{tabular}

* TLC, total lung capacity: RV, residual volume. Data are \% of predicted values (25).

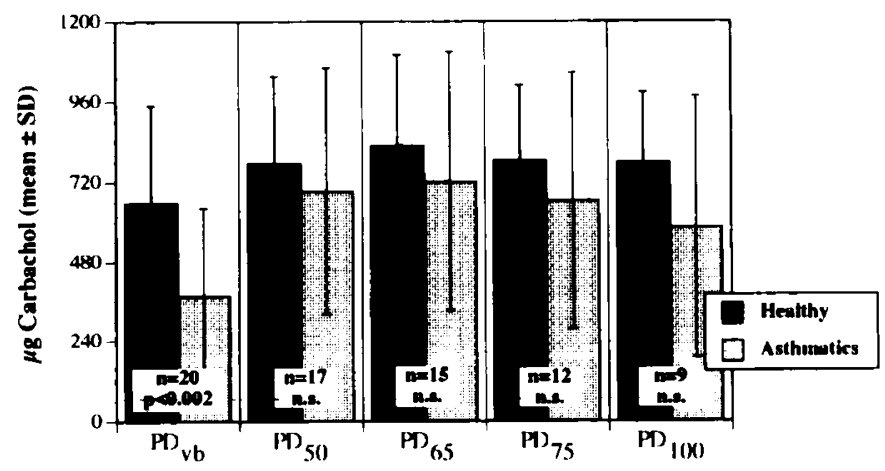

Fig. 2. Means and SD of PD obtained in 20 healthy and 20 asthmatic children.

Table 3. Accuracy of PD computed according to nonlinear model from complete dose response curves of 20 healthy and 20 asthmatic children tested by carbachol challenge test*

\begin{tabular}{ccccc}
\hline $\begin{array}{c}\text { Thresholds from } \\
\text { 4th power function }\end{array}$ & $\mathrm{PD}_{50}$ & $\mathrm{PD}_{65}$ & $\mathrm{PD}_{75}$ & $\mathrm{PD}_{100}$ \\
\hline $\begin{array}{c}\text { Healthy subjects }(n=20) \\
\mathrm{PD}(\mathrm{x})>\mathrm{R}_{\text {int }}(0)+2 \mathrm{SD} \\
(\text { above baseline range })\end{array}$ & 16 & 17 & 17 & 19 \\
$\begin{array}{c}P D(\mathrm{x})<\mathrm{R}_{\text {int }}(0)+2 \mathrm{SD} \\
\quad(\text { within baseline range })\end{array}$ & 4 & 3 & 3 & 1 \\
$\begin{array}{c}\text { Subjects accurately measured } \\
(\%)\end{array}$ & 80 & 85 & 85 & 95 \\
$\begin{array}{c}\text { Asthmatic children }(n=20) \\
\mathrm{PD}(\mathrm{x})>\mathrm{R}_{\text {int }}(0)+2 \mathrm{SD} \\
(\text { above baseline range })\end{array}$ & 18 & 20 & 20 & 20 \\
$\begin{array}{c}\mathrm{PD}(\mathrm{x})<\mathrm{R}_{\text {int }}(0)+2 \mathrm{SD} \\
(\text { within baseline range })\end{array}$ & 2 & 0 & 0 & 0 \\
$\begin{array}{c}\text { Patients accurately measured } \\
(\%)\end{array}$ & 90 & 100 & 100 & 100 \\
\hline
\end{tabular}

* $\mathrm{PD}(\mathrm{x})=$ either $\mathrm{PD}_{50}, \mathrm{PD}_{65}, \mathrm{PD}_{75}$, or $\mathrm{PD}_{100}$.

There is increasing concern that the end-expiratory resting level may change during the provocation procedure. In consequence, the dose-response curve of a bronchial challenge representing changes in airway mechanics may be significantly influ- enced by changes in volume history. Because of the difficult technical approach, we have not been able to verify this point in the present study. However, in another study we have been able to demonstrate the influence of the kind of functional abnormality (pulmonary hyperinflation, bronchial obstruction, or mixed type) as a confounding factor for the detection of bronchial hyperreactivity in asthmatic children (33). In addition, potential changes in end-expiratory resting level during a bronchial challenge may influence the exact detection of the degree of bronchial obstruction.

Reproducibility and ethical considerations. Carbachol is highly cumulative in its action. The pharmacologic property precludes repeating the test at short intervals, so that the reproducibility of the $\mathrm{PD}_{\mathrm{vb}}$ can be established in stable asthmatics in whom measurements are repeated on different days; this did not form part of the protocol and needs to be established in future studies. In view of the cumulative effects, we also recommend that the test be terminated by administration of a $\beta$-2-agonist, so that respiratory resistance is restored at a lower level. It follows that, for a repetition of a bronchial challenge, not only the previous challenging agent but in parallel also the interaction of the $\beta-2$ stimulator have to be considered. Each second test will unavoidably be influenced by the preceding test. When the second test is postponed until the next day, the patient, especially the asthmatic child, will naturally be in a different condition with respect to lung function. Therefore, it is extremely difficult to achieve identical baseline conditions. In consequence, it was deemed unethical to perform such repeated tests in children. Moreover, it is of utmost interest and of an urgent need to have clear recommendations for such research in pediatrics.

Practical aspects: alternative techniques. In an older age range of children, measurements using forced breathing maneuvers and taking the $\mathrm{FEV}_{1}$ as a target parameter to estimate the testinduced bronchial obstruction can be considered the gold standard. It was not a formed part of the present study and because of the age range of the study subjects $(5-15 y)$ it was not possible to compare the interruption technique with the technique using forced breathing maneuvers. However, such comparison was made in another group of older asthmatic children comparing $R_{\text {int }}$ with $F E V_{1}$ and $M E F_{50}$ at different provocation levels (unpublished data). In only $56 \%$ did $R_{\text {int }}$ behave similarly to $F E V_{1}$. The correlation largely depends on whether asthmatic children with pulmonary hyperinflation, bronchial obstruction, or both were investigated. The only other technique that does not involve a high degree of active cooperation is the forced oscillation technique $(41,42)$. However, this technique involves the patient maintaining a patent upper airway for several seconds. This was particularly difficult for young children. $R_{\text {int }}$ is measured during spontaneous airflow when momentary closure of the glottis does not occur. The advantages of calculating $\mathrm{PD}_{\mathrm{vb}}$ and its application to assessing BR are safety and accuracy. For practical purposes, there is no need to have a sophisticated curve-fitting model, which is time-consuming and does not reflect a biologic model applicable to both patients and healthy subjects. In addition, extrapolation must be avoided. For the present study, the number of PD that has to be judged "inaccurately assessed" can be obtained from Table 1 and Figure 2 (PDx > $1200 \mu \mathrm{g}$ of carbachol). The new technique features the additional advantage that the test procedure can be consistently shortened in time, because a much lower dose needs to be administered for even better $f$ and $s$. This latter point is also an argument for safety. We do not yet have sufficient experience with applying this technique to children aged 1 to $5 \mathrm{y}$, and so far, comparison with the technique previously worked out by Godfrey and coworkers (43-45) cannot be made. By this latter technique, lung sounds are recorded at the tracheal level for $1 \mathrm{~min}$ after nebulization of a bronchoconstricting drug and the concentration causing "wheeze" is taken as the target parameter. The validity of our test procedure and calculation of $\mathrm{PD}_{\mathrm{vb}}$ will be evaluated in much larger collectives, using the present algorhithm for measurements of respiratory system resistance. 


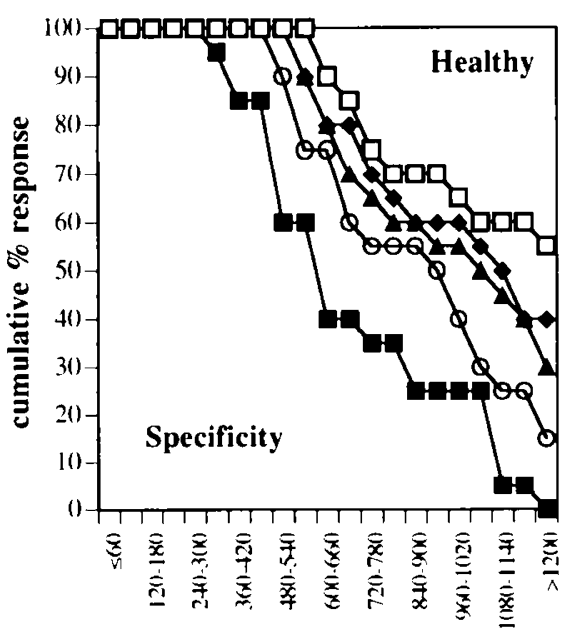

$\mu \mathrm{g}$ carbachol

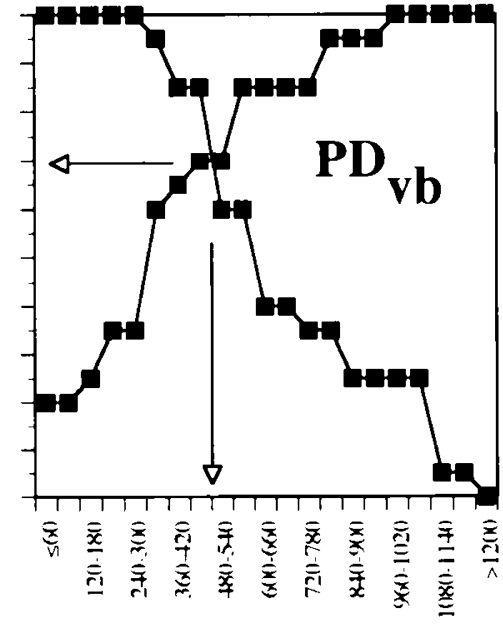

$\mu g$ carbachol

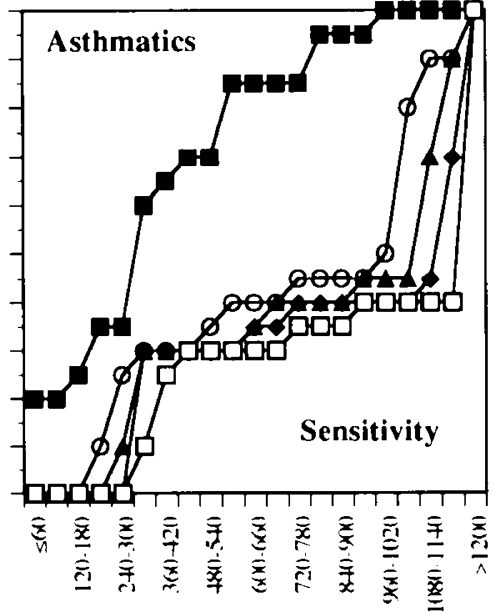

$\mu \mathrm{g}$ carbachol

$\rightarrow \mathrm{PD}_{\mathrm{vb}} \rightarrow \mathrm{PD50} \quad \longrightarrow$ PD65 $\rightarrow$ PD75

Fig. 3. Cumulative percent decline of $f$ and cumulative percent increase of $s$ for PD levels, obtained by bronchial challenge tests with carbachol in 20 healthy and 20 asthmatic children.

Acknowledgments. The authors thank Dr. H. Salvisberg, mathematician; Dr. Silvia Gschwend, M.D.: Beverley Meyer and Elisabeth Iten for technical assistance; and Michael Williams, B.A., for correcting the English text.

\section{REFERENCES}

1. Chai H, Farr RS. Froehlich LA. Mathison DA. McLean JA. Rosenthal RR. Sheffer AL. Spector SL. Townley RG 1975 Standardization of bronchial inhalation challenge procedures. J Allergy Clin Immunol 56:323

2. Orehek J. Gayrard P. Smith AP, Grimaud C. Charpin J 1977 Airway response to carbachol in normal and asthmatic subjects. Am Rev Respir Dis 115:937943

3. Boushey HA. Holtzman MJ, Sheller JR. Nadel JA 1980 Bronchial hyperreactivity. Am Rev Respir Dis 121:389-413

4. Hargreave FE. Ryan G. Thomson NC. O'Bryne PM. Latimer K. Juniper EF. Dolovich J 1981 Bronchial responsiveness to histamine or methacholine in asthma: measurement and clinical significance. J Allergy Clin Immunol 68:347-355

5. Eiser NM. MacRae KD. Guz A 198! Evaluation and expression of bronchial provocation tests. Bull Eur Physiopathol Respir 17:427-440

6. Hopp RJ, Bewtra AK. Nair NM. Townley RG 1984 Specificity and sensitivity of methacholine inhalation challenge in normal and asthmatic children. $J$ Allergy Clin Immunol 74:154-158

7. Neijens HJ. Degenhart HJ. Raatgeep HC. Kerrebijn KF 1979 Study on the significance of bronchial hyperreactivity in the bronchus obstruction after inhalation of cat dander allergen. J Allergy Clin Immunol 64:507-515

8. Gurwitz D. Corey M. Levison H 1980 Pulmonary function and bronchial reactivity in children after croup. Am Rev Respir Dis 122:95-99

9. Shapiro GG. Furukawa CT, Pierson WE. Bierman CW 1982 Methacholine bronchial challenge in children. J Allergy Clin Immunol 69:365-369

10. Weiss ST, Tager IB, Weiss JW, Munoz A. Speizer FE, Ingram RH 1984 Airways responsiveness in a population sample of adults and children. Am Rev Respir Dis 129:898-902

11. Hopp RJ, Bewtra AK. Nair NM, Townley RG 1985 The effect of age on methacholine response. J Allergy Clin Immunol 76:609-613

12. Hopp RJ. Bewtra AK. Nair NM, Watt GD. Townley RG 1986 Methacholine inhalation challenge studies in a selected pediatric population. Am Rev Respir Dis 134:994-998

13. Spiropoulos K. Stevens J. Eigen H. Spiropoulos A 1986 Specificity and sensitivity of methacholine challenge test in children with normal and hyperreactive airways. Acta Paediatr Scand 75:737-743

14. Salome CM, Peat JK. Britton WJ, Woolcock AJ 1987 Bronchial hyperresponsiveness in two populations of Australian schoolchildren. Clin Allergy $17: 271-281$

15. Peat JK, Britton WJ, Salome CM. Woolcock AJ 1987 Bronchial hyperresponsiveness in two population of Australian school-children. III. Effect of exposure to environmental allergens. Clin Allergy 17:291-300

16. Kraemer R. Sennhauser F, Reinhardt M 1987 Effects of regular inhalation of beclomethasone dipropionate and sodium cromoglycate on bronchial hyperreactivity in asthmatic children. Acta Paediatr Scand 76:119-123

17. Clifford RD, Radford M. Howell JB. Hollgate ST 1989 Prevalence of atopy and range of bronchial response to methacholine in 7 and 11 year old schoolchildren. Arch Dis Child 64:1126-1132

18. Gschwend-Eigenmann S. D'Apuzzo V. Schöni MH, Kraemer R 1989 Einfluss der Luftschadstoffbelastung auf gesunde und lungenkranke Kinder im Südtessin. Schweiz Med Wochenschr 119:1868-1874

19. Peat JK. Salome CM. Woolcock AJ 1990 Longitudinal changes in atopy during 4-year period: relationship to bronchial hyperresponsiveness and respiratory symptoms in a population sample of Australian schoolchildren. J Allergy Clin Immunol 85:65-74

20. Young S. Le Souëf. Geelhoed GC. Stick SM. Chir B. Turner KJ. Landau LI 1991 The influence of a family history of asthma and parental smoking on airway responsiveness in early infancy. N Engl J Med 325:1168-1173

21. Nair N. Hopp RJ. Alper BI. Bewtra AK. Townley RG 1986 Correlation of methacholine-induced non-specific bronchial reactivity and cold air hyperventilation challenge. Ann Allergy 56:226-228

22. Hopp RJ, Christy J. Bewtra AK, Nair NM. Townley RG 1987 Incorporation and analysis of ultrasonically nebulized distilled water challenges in an epidemiologic study of asthma and bronchial reactivity. Ann Allergy 60:129130

23. Kraemer R, Meister B, Schaad UB, Rossi E 1983 Reversibility of lung function abnormalities in children with perennial asthma. J Pediatr 102:347-350

24. Zeltner S, Sennhauser FH, Kraemer R 1986 Epidemiologische Aspekte des Asthma bronchiale im Kindesalter. Schweiz Med Wochenschr 112:12101216

25. Zapletal A, Samanek M. Paul T 1987 Lung function in children and adolescents. Methods, reference values. Prog Respir Res 22:113-218

26. van Neergaard K. Wirz K 1927 Die Messung der Strömungswiderstände in den Atemwegen des Menschen, insbesondere bei Asthma und Emphysem. Z Klin Med 105:51-82

27. Veuilleumier P 1944 Ueber eine Methode zur Messung des intraalveolaren Druckes und der Strömungswiderstände in den Atemwegen des Menschen. Z Klin Med 143:698-717

28. Mead J, Whittenberger JL 1954 Evaluation of the airway interruption technique as method for measuring pulmonary airflow resistance. J Appl Physiol 6:408-416

29. Vooren PH 1976 Meting van de ademweerstand met de interruptiemethode (Measurement of respiratory resistance by the method of interruption of the air flow). Thesis, University of Leiden. The Netherlands

30. Jackson AC, Milhorn HT, Norman JR 1974 A reevaluation of interrupter technique for airway resistance measurements. J Appl Physiol 36:264-268

31. Frey U, Kraemer R 1990 Visco-elastic properties of the lung, assessed by the flow-interruption technique in children. Am Rev Respir Dis 141:A714(abstr)

32. Charpin D. Badier M. Orehek J 1985 Dose-response curves to inhaled carbachol in asthma and chronic bronchitis. Bull Eur Physiopathol Respir 21:417-420

33. Wirz C. Maibach R, Kraemer R 1990 Concomitant factors influencing determination of bronchial reactivity in children. Am Rev Respir Dis 141:A902(abstr)

34. Wirz C. Kraemer R 1990 Bronchial reactivity to inhaled carbachol in children: assessment by PD50, PD65, PD75, PDi00. Eur J Respir Dis 3 (Suppl 10):133a(abstr)

35. Bates JHT, Baconnier P, Milic-Emili J 1988 A theoretical analysis of interrupter technique for measuring respiratory mechanics. J Appl Physiol 64:22042214

36. Bates JHT, Sly PD. Kochi T. Martin JG 1987 The effect of a proximal compliance on interrupter measurements of resistance. Respir Physiol $70: 301-312$

37. Bates JHT. Ludwig MS. Sly PD. Brown K. Martin JG. Fredberg JJ 1988 
Interrupter resistance elucidated by alveolar pressure measurement in openchest normal dogs. J Appl Physiol 65:408-414

38. Bates JHT, Brown KA. Kochi T 1989 Respiratory mechanics in the normal dog determined by expiratory flow interruption. J Appl Physiol 67:22762285

39. Bates JHT, Abe T, Romero PV, Sat J 1989 Measurements of alveolar pressure in closed chested dogs during flow interruption. J Appl Physiol 67:488-492

40. Chowienczyk PJ, Lawson CP. Lane S, Johnson. Wilson N. Silverman M Cochrane GM 1991 A flow interruption device for measurement of airway resistance. Eur Respir J 4:623-628

41. Dubois AB. Brody AW. Lewis DH. Burgess BF 1958 Oscillation mechanics of lungs and chest in man. J Appl Physiol 8:587-594
42. Michaelson ED. Grassman ED. Peters WR 1975 Pulmonary mechanics by spectral analysis of forced random noise. J Clin Invest 56:1210-1230

43. Avital A. Bar-Yishay E. Springer C. Godfrey S 1988 Bronchial provocation tests in young children using tracheal auscultation. J Pediatr 112:591-594

44. Avital A. Noviski N. Bar-Yishay E. Springer C. Levy M. Godfrey S 1991 Nonspecific bronchial reactivity in asthmatic children depends on severity but not on age. Am Rev Respir Dis 144:36-38

45. Noviski N, Cohen L. Springer C. Bar-Yishay E. Godfrey S 1991 Bronchial provocation determined by breath sounds compared with lung function. Arch Dis Child 66:952-955

\section{Announcement}

\section{Paediatric Week Holland}

The Paediatric Week Holland will be organized in Rotterdam. The Netherlands from June 29 to July 6, 1994. From July 3 through July 6, a combined meeting will be held of the European Society for Paediatric Research. the European Paediatric Respiratory Society, the European Respiratory Society-Paediatric Assembly, the European Society of Paediatric Allergy/Clinical Immunology, the European Society for Paediatric Infectious Diseases. the European Society of Paediatric Intensive Care. and the European Society for Paediatric Hematology and Immunology. From June 29 through July 2, the British Association of Paediatric Surgeons will meet, and the Dutch Society of Psychosocial Consultation and Paediatrics will meet from July 3 through July 5 . Postgraduate courses will be organized in the overlapping weekend. For further information, please contact: Pieter J. J. Sauer. M.D., \% Erasmus University Rotterdam, P.O. Box 1738, NL-3000 DR Rotterdam. The Netherlands. 